\title{
Preparation of Orally Disintegrating Tablets Containing Powdered Tea Leaves with Enriched Levels of Bioactive Compounds by Means of Microwave Irradiation Technique
}

\author{
Hironori Tanaka, ${ }^{a}$ Yasunori Iwao, ${ }^{*, a}$ Masahiro Izumikawa, ${ }^{a}$ Syusuke Sano,${ }^{b}$ Hitoshi Ishida, ${ }^{a}$ \\ Shuji Noguchi, ${ }^{a}$ and Shigeru Itai ${ }^{a}$ \\ ${ }^{a}$ School of Pharmaceutical Sciences, University of Shizuoka; 52-1 Yada, Suruga-ku, Shizuoka 422-8526, Japan: and \\ ${ }^{b}$ Pharmaceutical Science and Technologies, Eisai Co., Ltd.; 1 Kawashimatakehaya-machi, Kakamigahara, Gifu \\ 501-6195, Japan \\ Received March 3, 2016; accepted May 30, 2016
}

In the present study, a microwave treatment process has been applied to prepare orally disintegrating tablets (ODTs) containing powdered tea leaves with enriched levels of the anti-inflammatory compounds such as chafuroside A (CFA) and chafuroside B (CFB). The use of distilled water as the adsorbed and granulation solvents in this preparation process afforded tablets with a long disintegration time (more than $120 \mathrm{~s}$ ). The CFA and CFB contents of these tablets did not also change after $4 \mathrm{~min}$ of microwave irradiation due to the tablet temperature, which only increased to $100^{\circ} \mathrm{C}$. In contrast, the tablet temperature increased up to $140^{\circ} \mathrm{C}$ after $3 \mathrm{~min}$ of microwave irradiation when a $1.68 \mathrm{M} \mathrm{Na}_{2} \mathrm{HPO}_{4}$ solution instead of distilled water. Notably, the disintegration time of these tablets was considerably improved (less than $20 \mathrm{~s}$ ) compared with the microwaveuntreated tablets, and there were 7- and 11-fold increases in their CFA and CFB contents. In addition, the operational conditions for the preparation of the tablets were optimized by face-centered composite design based on the following criteria: tablet hardness greater than $13 \mathrm{~N}$, disintegration time less than $30 \mathrm{~s}$ and friability less than $\mathbf{0 . 5 \%}$. The requirements translated into $X_{1}$ (the amount of granulation solvent), $X_{2}$ (tableting pressure) and $X_{3}$ (content of the powdered tea leaves) values of $45 \%, 0.43 \mathrm{kN}$ and $32 \%$, respectively, and the ODTs containing powdered tea leaves prepared under these optimized conditions were found to show excellent tablet properties and contain enriched levels of CFA and CFB.

Key words orally disintegrating tablet; microwave; powdered tea leaf; wet molded tablet; chafuroside A; chafuroside B

Tea is one of the most widely consumed beverages in the world, especially in Asian countries such as China and Japan. Tea leaves contain a variety of active ingredients, including polyphenolic compounds (e.g., catechins) and amino acids (e.g., theanine), which exhibit anti-oxidative, anti-inflammatory and anti-carcinogenic effects. ${ }^{1-4)}$ Tea leaves are not only ingested as beverages but can also be consumed as dietary supplements and pharmaceutical products, ${ }^{5)}$ where the active constituents in the tea leaves are used to provide certain health benefits. ${ }^{6}$ In fact, a wide range of health food supplements containing finely powdered tea leaves has been marketed around the world for numerous indications. ${ }^{7)}$ However, it can be quite difficult for certain groups of individuals (e.g., pediatric and geriatric patients with dysphagia) to take several powdered tea tablets every day and enjoy the potential benefits afforded by these health food supplements. ${ }^{8)}$ To improve patient compliance and the QOL offered to geriatric patients by these health food supplements, it would be useful to achieve the development of orally disintegrating tablets (ODTs) based on powdered tea leaves that could rapidly dissolve in the oral cavity with minimal water. ${ }^{9-11)}$ The preparation of ODTs containing powdered tea leaves would therefore make it much easier to provide health food supplements to elderly patients with dysphagia and pediatric patients. Despite the potential benefits of ODTs in this regard, there have been no reports in the literature to date pertaining to the development of ODTs composed of powdered tea leaves.

A wide range of different technologies have been developed for the preparation of ODTs, including lyophilization, ${ }^{12,13)}$ wet molding ${ }^{14)}$ and dry granulation methods. ${ }^{15,16)}$ However, tea leaves themselves mainly consist of cellulose, and powdered tea leaves show high levels of water absorption, low flowability and low compressibility, $\left.{ }^{17}\right)$ which makes them difficult to handle in terms of their application to existing ODT technologies. We have recently developed a novel method for the facile preparation of ODTs by applying microwave technology to wet molded tablets containing mannitol, sugar alcohol, polymeric disintegrant and water absorption materials. ${ }^{18-20)}$ The microwave irradiation of wet molded tablets containing mannitol led to the formation of water vapor, which resulted in the expansion of the pores inside the tablets and the formation of new void networks. These new void networks allowed for the tablets to be penetrated more efficiently by water and resulted in a decrease in their disintegration time. In addition, the formation of water vapor during the microwave irradiation of these tablets also led to the dissolution/precipitation of some of the mannitol particles on the surface, which led to the formation of new solid bridges. The formation of new solid bridges between the mannitol particles led to an increase in the hardness of the tablets. Taken together, this new method for the microwave irradiation of wet molded tablets therefore makes it possible to prepare ODTs with opposing physicochemical properties such as rapid disintegration time and enhanced hardness. It was envisaged that this technique could be used for the preparation of ODTs containing powdered tea leaves because powdered tea leaves can absorb large amounts 
of water. Ortiz et al. reported that tea leaves can absorb up to $30 \%$ of their weight in water, ${ }^{21)}$ which means that powdered tea leaves could be subjected to the microwave irradiation method described above without the need for any other water absorption materials. Because water has been used previously as an absorption and granulation solvent for the wet granulation of tablets for microwave irradiation, there would be no need for complicated operational conditions to improve the flowability of the particles such as fluidized bed granulation. This would therefore eliminate any difficulties associated with the handling of the powdered tea leaves.

One of the other advantages of using a microwave irradiation technique for the preparation of tablets containing powdered tea leaves is the possibility that this process could lead to the formation of active ingredients from otherwise inactive precursor materials during the manufacturing process. Previous reports have shown that the extraction and purification of the active ingredients from plants such as tea under high temperature conditions effectively enhanced the conversion of precursor materials to active ingredients. For example, Ishida reported that heating methanol extracts of oolong tea leaves at $160^{\circ} \mathrm{C}$ for $80 \mathrm{~min}$ led to the successful conversion of the precursor materials isovitexin $2^{\prime \prime}$-sulfate (Pre chafuroside A [CFA]) and vitexin 2"-sulfate (Pre chafuroside B [CFB]) to CFA and CFB, respectively. ${ }^{22)}$ It is noteworthy that this process led to a 180 -fold increase in the concentration of these compounds in the methanol extract (CFA: $50.4 \mathrm{ng} / \mathrm{g}$, CFB: $38.7 \mathrm{ng} / \mathrm{g}){ }^{22,23)}$ This result suggested that the application of a similar technique to powdered tea leaves under high moisture conditions would allow for the efficient conversion of any precursor materials to active ingredients during just the manufacturing process and avoid the need for any complicated extraction processes. CFA and CFB have recently attracted considerable interest from researchers working in numerous fields because they possess a broad range of pharmacological properties such as anti-oxidative, anti-inflammatory and antiallergic activities. ${ }^{22,24)}$ For example, a low dose of CFA $(10 \mu \mathrm{g} /$ $\mathrm{kg}$ ) has been shown to exhibit significant anti-inflammatory activity in an atopic 2,4-dinitrofluorobenzene-induced rat model of skin inflammation and this anti-inflammatory activity exhibited similar to that of the anti-inflammatory steroidal agents prednisolone $(10 \mathrm{mg} / \mathrm{kg})$ and betamethasone $(0.8 \mathrm{mg} /$ $\mathrm{kg}$ ), which indicated that CFA could be used as a novel alternative to steroids. It is also envisaged that CFA and CFB could play an active role in the development of new cosmetics because they have been reported to show excellent anti-wrinkle activity. ${ }^{25,26)}$ Although there are numerous potential applications for CFA and CFB, these compounds have only ever been isolated in small quantities from oolong tea leaves. ${ }^{22,23)}$ With this in mind, it was envisaged that orally disintegrating tea tablets (ODTTs) containing much larger amounts of these active ingredients could be prepared by the microwave irradiation of wet molded tablets, without the need for any additional operations such as extraction. Furthermore, because these tablets would be roasted at high temperature by microwave irradiation, the resulting ODTTs would most likely possess an inoffensive aroma. This could lead to an improvement in the QOL of patients taking these tablets, further highlighting the clinical significance of ODTTs.

Based on these background, the primary aim of this study was to prepare ODTTs with excellent tablet properties that contain high levels of chafurosides. The secondary aim of this study was to optimize the formulation of these tablets using statistically-driven experimental design methods.

\section{Experimental}

Materials Oolong tea leaves, which are also known as Houousuisen, were purchased from the "Banboo chakan" Chinese tea ceremony (Kochi, Japan). D-Mannitol was purchased in its $\beta$ crystalline form from Merck Ltd. (Tokyo, Japan). Low-substituted hydroxypropyl cellulose (L-HPC) (mean particle size: $45 \mu \mathrm{m}$ and hydroxyepoxy group NBD-020) was supplied by Shin-Etsu Chemical Co., Ltd. (Tokyo, Japan). Polyvinylpyrrolidone $\left(K_{0}\right.$ llidon $\left.{ }^{\circledR} 25\right)$ was supplied by BASF Japan (Tokyo, Japan).

Preparation of ODTTs Preparation of ODTTs was performed according to the modified method of our previous literature. ${ }^{20)}$ The oolong tea leaves were ground using a standard tea grinder (Teafine, Mutow, Shizuoka, Japan), and the resulting powder was sieved through a $44-\mu \mathrm{m}$ sieve screen before being weighed $(240 \mathrm{mg})$ and placed in a mortar. Distilled water $(40 \% \mathrm{w} / \mathrm{w}$ versus the weight of powdered tea leaves) was then dropped into the mortar as an adsorption solvent using a pipette, and the resulting mixture was stirred using a pestle to obtain a homogenous mixture. D-Mannitol (464 mg), L-HPC $(80 \mathrm{mg})$ and polyvinylpyrrolidone $(16 \mathrm{mg})$ were then added to the mortar, and the resulting mixture was blended with the pestle. An additional portion of distilled water (30\% $\mathrm{w} / \mathrm{w}$ versus the total weight of the powdered tea leaves) was then added to the mortar as a granulation solvent, and the resulting mixture was granulated for approximately $2 \mathrm{~min}$. A portion $(60 \mathrm{mg})$ of the wet granules was compressed using a compression test apparatus (MPC-100, Okada Seiko, Tokyo, Japan) fitted with several punches of $5 \mathrm{~mm}$ in diameter. A compression force of $0.5 \mathrm{kN}$ was used for the preparation of the tablets. The wet molded tablets were heated under microwave irradiation using a microwave oven (NE-EH226, Panasonic, Osaka, Japan) at $500 \mathrm{~W}$ for $1-4 \mathrm{~min}$. After microwave treatment, the tablets were dried in a thermostatic chamber at $80^{\circ} \mathrm{C}$ for $24 \mathrm{~h}$.

\section{Characterization of ODTTs}

Swelling Degree

The degree of swelling was defined according to the following equation:

$$
\text { Swelling degree }=\text { Thickness }_{\text {Treated }}-\text { Thickness }_{\text {Untreated }}
$$

Where Thickness ${ }_{\text {Treated }}$ and Thickness ${ }_{\text {Untreated }}$ are the thicknesses of the microwave-treated and untreated tablets, respectively. The thickness of each tablet was measured with a micrometer with a precision of $0.01 \mathrm{~mm}$ (CD-20, Mitsutoyo Corporation, Kanagawa, Japan). Nine tablets were randomly selected for thickness measurements and the average values were used for the subsequent calculations.

\section{Disintegration Time}

Disintegration time was measured using an orally disintegrating tablet tester (Tricorptester, Okada Seiko, Tokyo, Japan). Artificial saliva consisting of distilled water $(500 \mathrm{~mL})$, $\mathrm{NaCl}(0.77 \mathrm{~g}), \mathrm{KCl}(0.74 \mathrm{~g})$ and Tween 80 (1.5 g) was used as a test solution. A tablet was put on the mesh (diameter: $3.2 \mathrm{~mm}$ ) and covered with another mesh (diameter: $2.1 \mathrm{~mm}$ ) fastened with slide rails, with $40 \mathrm{~g}$ ring-shaped weight on the 
upper mesh as a load. The temperature of the test solution was kept at $37^{\circ} \mathrm{C}$ using a water bath, and the dropping rate of the solution was set at $6 \mathrm{~mL} / \mathrm{min}$. These test conditions were already set by Hoashi et al. and they reported high correlation between in vivo and in vitro disintegration times under these conditions. ${ }^{27)}$ The maximum disintegration time for these experiments was set to $120 \mathrm{~s}$. All of these measurements were repeated three times and the average values were calculated.

Tablet Hardness

The tablet fracture strength was defined as the force required for breaking the tablet by radial compression. The tablet hardness was determined using a tablet hardness tester (PC30, Okada Seiko). All of these measurements were repeated three times and the average values were calculated.

Friability

The tablet friability was determined using a tablet friability tester (Friabilator, Toyama Sangyo, Osaka, Japan) in accordance with the procedure described in the sixteenth edition of the Japanese Pharmacopoeia (JP16th). All of these measurements were repeated three times and the average values were calculated.

Surface Temperature of Tablets

The surface temperature of the tablets was measured immediately after the microwave irradiation process using a thermal imaging camera (FLIR i7, Chino, Tokyo, Japan). All of these measurements were repeated nine times and the average values were calculated.

Determination of Chafuroside Derivative Amounts

The ODTTs prepared in this study were crushed in a pestle and mortar, and the resulting powder was placed in a test tube followed by $50 \%$ methanol $(10 \mathrm{~mL})$. The methanolic mixture was then stirred with a stirrer bar in a hot water bath at $80^{\circ} \mathrm{C}$ for $20 \mathrm{~min}$. The mixture was then sonicated for $1 \mathrm{~min}$ before being centrifuged at $10000 \times \boldsymbol{g}$ for $5 \mathrm{~min}$. The supernatant was collected and analyzed by LC-MS/MS (API2000, Agilent, CA, U.S.A.) to determine the amounts of CFA, CFB, Pre CFA and Pre CFB according to the method of previous literature. ${ }^{23)}$ All of these measurements were repeated three times and the average values were calculated.

Screening of Buffers Solutions of $\mathrm{NaCl}, \mathrm{KCl}, \mathrm{NaH}_{2} \mathrm{PO}_{4}$. $2 \mathrm{H}_{2} \mathrm{O}, \mathrm{Na}_{2} \mathrm{HPO}_{4} \cdot 12 \mathrm{H}_{2} \mathrm{O}, \mathrm{Na}_{3}\left[\mathrm{C}_{3} \mathrm{H}_{5} \mathrm{O}(\mathrm{COO})_{3}\right] \cdot 2 \mathrm{H}_{2} \mathrm{O}, \mathrm{CaCl}_{2} \cdot 2 \mathrm{H}_{2} \mathrm{O}$ and $\mathrm{MgCl}_{2}$ were screened as potential high thermal conductivity solutions for the preparation of the ODTTs. All of the salt solutions were prepared at a concentration of $1.68 \mathrm{M}$. These salt solutions were then used instead of distilled water as the adsorption and granulation solvents for the preparation of the ODTTs. With the exception of the solvent, the ODTTs were prepared according to the methods described above. The molded tablets prepared using the salt solution were heated under microwave irradiation and the surface temperature of the tablets was measured at 1, 2, 3 and $3.5 \mathrm{~min}$. All of these measurements were repeated nine times and the average values were calculated.

Experimental Design Face-centered composite design was used to analyze the relationship between the variables under investigation, as well as the tablet properties and the active ingredients, as shown in Table 1 . The amount of granulation solvent $\left(X_{1}\right)$, tableting pressure $\left(X_{2}\right)$ and powdered tea leaf content $\left(X_{3}\right)$ were selected as variables. The central experimental points were performed in triplicate to evaluate and mitigate the potential for any experimental errors. The pre-
Table 1. Process Parameters and Operating Limits

\begin{tabular}{cccc}
\hline \hline Parameter & $\begin{array}{c}\text { Low } \\
(-1)\end{array}$ & $\begin{array}{c}\text { Center } \\
(0)\end{array}$ & $\begin{array}{c}\text { High } \\
(+1)\end{array}$ \\
\hline$X_{1}$ : Granulation solvent $(\%)$ & 30 & 40 & 50 \\
$X_{2}$ : Tableting pressure $(\mathrm{kN})$ & 0.3 & 0.4 & 0.5 \\
$X_{3}$ : Content of powdered tea leaves $(\%)$ & 20 & 30 & 40 \\
\hline
\end{tabular}

mix used in this experimental design method consisted of the same ratio of D-mannitol (6.63 g), L-HPC NBD-020 (1.12 g) and polyvinylpyrrolidone $(0.23 \mathrm{~g})$ as that used previously to evaluate the effects of changes in content of the powdered tea leaves. Furthermore, the methods used for the preparation of the ODTTs with the pre-mix material were the same as those described above. For each batch, the duration of microwave irradiation was set to the time when the surface temperature of the tablets reached $135-145^{\circ} \mathrm{C}$ because the contents and microwave heating efficiencies of the different salt solutions varied considerably.

Statistical Analysis Statistical analyses were performed using the unscrambler X 10.3 (CAMO Software Japan, Tokyo, Japan) and JMP 9 (SAS, Tokyo, Japan) programs to determine the significance of each major factor, as well as their interactions with the tablet properties and active ingredient contents. The formulation used for the preparation of the ODTTs was optimized based on the multiple regression equation generated using JMP. The significance probability for the regression coefficient was determined to be statistically significant for $p$ values of less than 0.05 . Student's $t$-test was also used to analyze the differences between the untreated and microwavetreated tablets, as well as the differences between the tablets subjected to microwave irradiation for $1 \mathrm{~min}$ and those treated for a longer period of time. $p$-Values of less than 0.05 were considered statistically significant.

\section{Results and Discussion}

Properties of ODTTs Prepared Using Distilled Water The degree of swelling, disintegration time, hardness and friability properties of the tablets prepared using distilled water are shown in Figs. 1A-D. As shown in Fig. 1A, the degree of swelling of the tablets that had been subjected to microwave irradiation for $1 \mathrm{~min}$ was $0.04 \mathrm{~mm}$. This value increased to about $0.2 \mathrm{~mm}$ for tablets that had been subjected to microwave irradiation for $2-4 \mathrm{~min}$. The results of our previous study showed that a degree of swelling of $0.2 \mathrm{~mm}$ was sufficient for shortening the disintegration time of ODTs. ${ }^{18)}$ As shown in Fig. 1B, there was no discernible difference in the disintegration times of tablets prepared with microwave irradiation times of 0 and $1 \mathrm{~min}$. However, the disintegration times of the tablets prepared with microwave irradiation times of $2 \mathrm{~min}$ or more were much longer $(>120 \mathrm{~s})$ than those prepared with microwave irradiation times of 0 or $1 \mathrm{~min}$. As shown in Fig. $1 \mathrm{C}$, the hardness of the tablets prepared without microwave irradiation was $10 \mathrm{~N}$. The hardness of the tablets increased significantly depending on the microwave irradiation time, with a microwave irradiation time of 4 min giving a tablet hardness of $44 \mathrm{~N}$. As shown in Fig. 1D, the friability of the tablets without microwave irradiation was determined to be $0.8 \%$. The subsequent heating of the tablets under microwave irradiation led to a microwave irradiation time-dependent decrease in the friability, with an irradiation time of $4 \mathrm{~min}$ affording a friabil- 
A

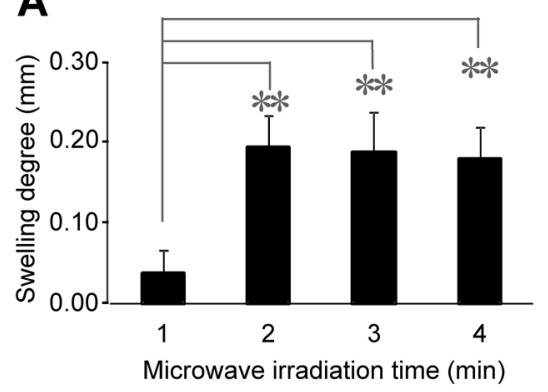

C

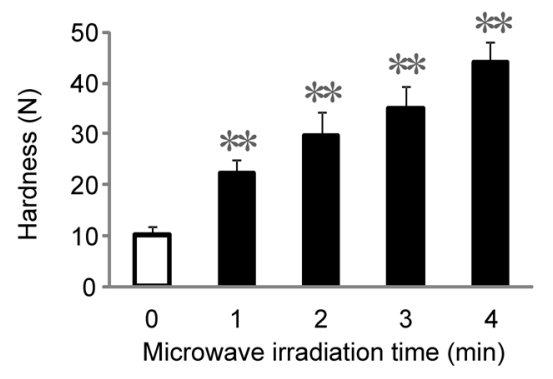

E

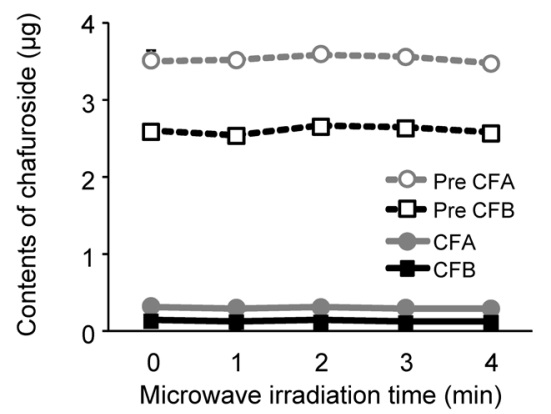

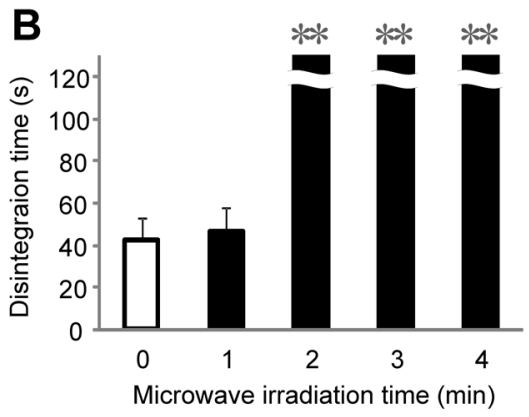

D

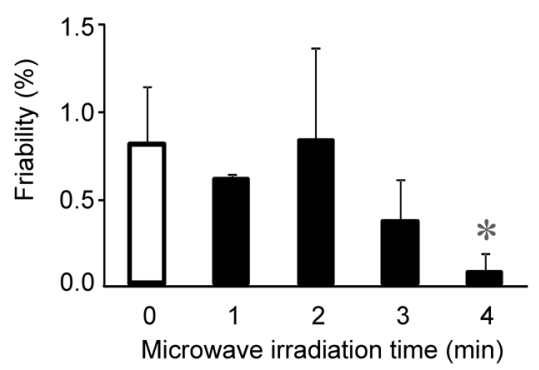

F

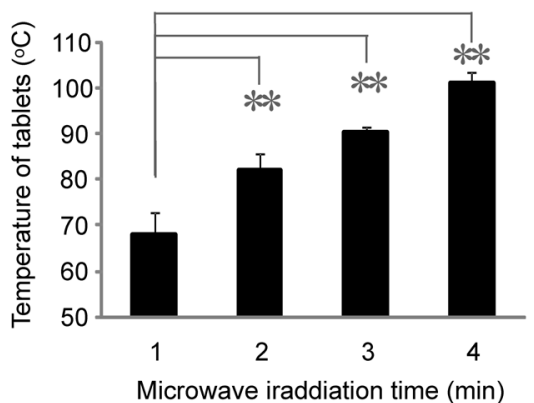

Fig. 1. Effect of Microwave Treatment on the Properties of the ODTTs Manufactured Using Distilled Water as the Adsorbed and Granulation Solvents

(A) Swelling degree, (B) disintegration time, (C) hardness, (D) friability, (E) Pre CFA, Pre CFB, CFA and CFB contents, and (F) tablet temperature of the ODTTs. ${ }^{*} p<0.05,{ }^{* *} p<0.01$ versus the microwave-untreated tablet or microwave-treated tablet for $1 \mathrm{~min}$.

ity of $0.1 \%$.

Although it was expected that an increase in the degree of the swelling of the microwave-irradiated tablets would lead to greater water penetration, the results of the current study revealed that the degree of swelling had no effect on the disintegration time of the tablets. This observation can be explained as follows. First, the powdered tea leaves in the tablets could have aggregated ${ }^{28)}$ and become unevenly distributed during the manufacturing process, which would lead to variations in the amount of water vapor being formed throughout the tablet during the microwave irradiation process. This would consequently lead to the dissolution of different amounts of mannitol and the formation of stronger cross-linking interactions. Second, given that powdered tea leaves are highly hygroscopic, ${ }^{17,21)}$ the tablets could absorb water and swell, which would prevent the penetration of water into the tablets. Furthermore, it was assumed that the formation of strong cross-linking interactions would lead to a microwave irradiation timedependent increase in the hardness of the tables, as well as a decrease in their friability. Taken together, these results suggested that we could prepare tablets containing powdered tea leaves with sufficient hardness and friability properties using a microwave irradiation method. However, the current method would lead to a significant increase in the disintegration time of the tablets. According to the Food and Drug Administration (FDA), ODTs should disintegrate within $30 \mathrm{~s}$. Given that the disintegration time of the tablets would be delayed because of the properties of the powdered tea leaves, we investigated several alternative methods for improving the disintegration time as the ODTTs.

In addition to the tablet properties, we also investigated the impact of the microwave irradiation process on the amounts of the different active ingredients (i.e., CFA, CFB, Pre CFA, Pre CFB) in the ODTTs. Each untreated ODTT contained $0.30 \mu \mathrm{g}$ of CFA, $0.13 \mu \mathrm{g}$ of $\mathrm{CFB}, 3.5 \mu \mathrm{g}$ of Pre CFA and $2.6 \mu \mathrm{g}$ of Pre CFB (18 mg of powdered tea leaves per tablet). However, no changes were observed in the amounts of these active ingredients under any of the microwave irradiation conditions evaluated in the current study, which demonstrated that this process did not induce the conversion of Pre CFA or Pre CFB to CFA and $\mathrm{CFB}$, respectively. The results of previous work in this area have shown that the extraction of plant material under high temperature conditions such as $160^{\circ} \mathrm{C}$ can result in high levels of conversion of precursor compounds to the corre- 
sponding active materials. ${ }^{22,23)}$ This result therefore suggested that the temperatures used for the microwave irradiation of the tablets in the current study were insufficient to allow for the conversion of the precursors to the corresponding active ingredients. As shown in Fig. 1F, the surface temperatures of the tablets were measured using a thermal imaging camera immediately after they had been subjected to the microwave irradiation process. The surface temperature of the tablets after $1 \mathrm{~min}$ of microwave irradiation was $68^{\circ} \mathrm{C}$. Increasing the time allowed for the microwave irradiation led to a significant increase in the temperature of the tablet surface, with an irradiation time of $4 \mathrm{~min}$ resulting in a surface temperature of $101^{\circ} \mathrm{C}$.

The main objectives of the current study were to not only prepare ODTTs with excellent tablet properties by microwave irradiation but to also prepare ODTTs that contained high levels of CFA and CFB. To achieve these objectives, we would need to identify another way in which to increase the temperature of the microwave irradiation process. By further increasing the temperature experienced by the tablets during the microwave irradiation process, it could be possible to not only enhance the conversion of Pre CFA and Pre CFB to CFA and $\mathrm{CFB}$, but to also shorten the disintegration time by increasing the swelling of the tablets.

A

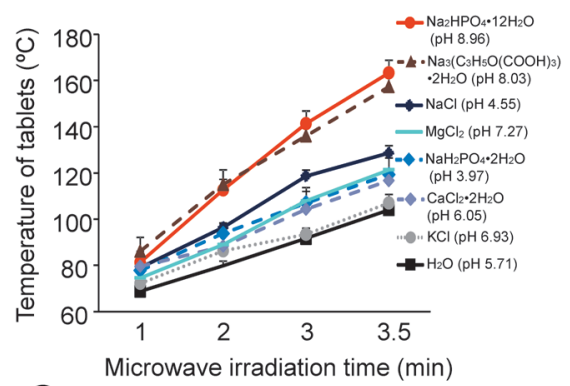

C

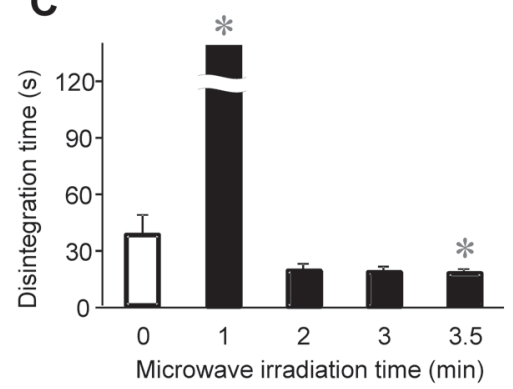

E

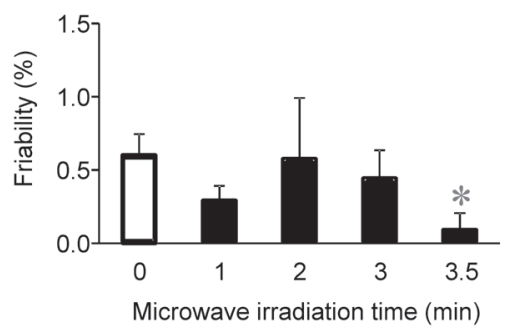

Screening of Buffers

DiGuilio and Teja reported that the thermal conductivity of distilled water could be increased by the addition of different salts, ${ }^{29)}$ which suggested that tablets prepared using a salt solution could reach higher temperatures under microwave irradiation conditions than those prepared using only water. Moreover, Ishida showed that Pre CFA and Pre CFB were converted to CFA and CFB much more readily under alkaline conditions, and that significant increases in the CFA and CFB contents were observed with increasing $\mathrm{pH}^{30,31)}$ Based on these results, we investigated the effects of seven different salt solutions with different $\mathrm{pH}$ properties as the adsorption and granulation solvents for the formulation of the tablets.

Figure 2A shows the effect of different temperatures on the tablets prepared using the different salt solutions and $\mathrm{pH}$ values. Increases in the tablet temperature were observed for all of the salt solutions compared with the tablets prepared using only distilled water. In particular, the surface temperatures of the tablets prepared using a $1.68 \mathrm{M}$ solution of $\mathrm{Na}_{2} \mathrm{HPO}_{4} \cdot 12 \mathrm{H}_{2} \mathrm{O}\left(\mathrm{pH}\right.$ 8.96) or $\mathrm{Na}_{3}\left(\mathrm{C}_{3} \mathrm{H}_{5} \mathrm{O}(\mathrm{COO})_{3}\right) \cdot 2 \mathrm{H}_{2} \mathrm{O}(\mathrm{pH}$ 8.03 ) increased significantly up to $140^{\circ} \mathrm{C}$ following $3 \mathrm{~min}$ of microwave irradiation. The use of a $\mathrm{NaCl}$ solution also led to a significant increase in the temperature of the tablets, with the surface temperature reaching up to $120^{\circ} \mathrm{C}$ following $3 \mathrm{~min}$

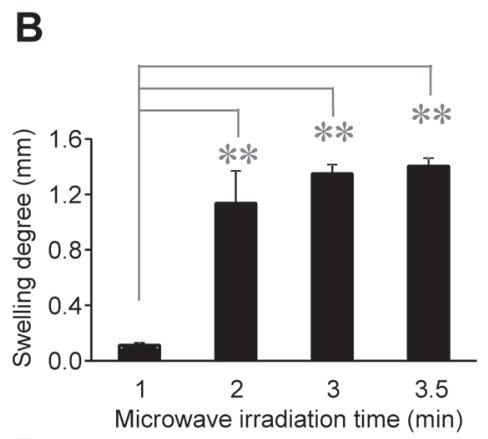

D
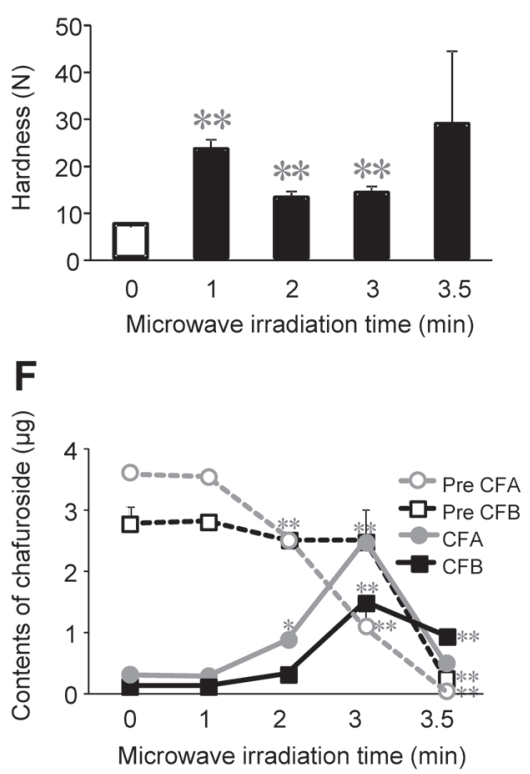

Fig. 2. Effect of Microwave Treatment on the Properties of the ODTTs Manufactured Using a $1.68 \mathrm{M} \mathrm{Na}_{2} \mathrm{HPO}_{4} \cdot 12 \mathrm{H}_{2} \mathrm{O}$ Solution as the Adsorbed and Granulation Solvents

(A) Screening of salt solutions with different $\mathrm{pH}$ values to increase the tablet temperature, (B) swelling degree, (C) disintegration time, (D) hardness (E), friability and (F) Pre CFA, Pre CFB, CFA and CFB contents of the ODTTs. * $p<0.05$, ** $p<0.01$ versus the microwave-untreated tablet or microwave-treated tablet for 1 min. 
of microwave irradiation. This increase in the temperature could be attributed to the nature and number of the metal ions contained in one molecule of the salt. Based on these results, $\mathrm{Na}_{2} \mathrm{HPO}_{4} \cdot 12 \mathrm{H}_{2} \mathrm{O}$ was selected as the best salt solution for use as an adsorption and granulation solvent because it led to the biggest increase in the surface temperatures of the tablets (up to $140^{\circ} \mathrm{C}$ ) and was the most alkaline of all of the solutions tested in the current study.

Properties of ODTTs Prepared Using $\mathrm{Na}_{2} \mathrm{HPO}_{4} \cdot 12 \mathrm{H}_{2} \mathrm{O}$ Solution

The degree of swelling, disintegration time, hardness and friability properties of the tablets prepared using the $\mathrm{Na}_{2} \mathrm{HPO}_{4} \cdot 12 \mathrm{H}_{2} \mathrm{O}$ solution are shown in Figs. 2B-E. As shown in Fig. 2B, the degree of swelling of the tablets prepared using a $\mathrm{Na}_{2} \mathrm{HPO}_{4} \cdot 12 \mathrm{H}_{2} \mathrm{O}$ solution was found to be $0.1 \mathrm{~mm}$ after $1 \mathrm{~min}$ of microwave irradiation. Surprisingly, the degree of swelling of these tablets, however, increased significantly to $>1.0 \mathrm{~mm}$ when they were heated under microwave irradiation for $2 \mathrm{~min}$ or more. Compared with the tablets prepared using only distilled water (Fig. 1A), the degree of swelling of the tablets prepared using the $\mathrm{Na}_{2} \mathrm{HPO}_{4} \cdot 12 \mathrm{H}_{2} \mathrm{O}$ solution increased significantly after a microwave irradiation time of $2 \mathrm{~min}$. This increase in the degree of swelling was attributed to the use of a $1.68 \mathrm{M}$ solution of $\mathrm{Na}_{2} \mathrm{HPO}_{4} \cdot 12 \mathrm{H}_{2} \mathrm{O}$ as the adsorption and granulation solvents. The use of this salt solution led to an increase in the temperature of the tablet during the microwave irradiation process, which would have led to an increase in the force with which the water vapor was distributed within the tablets. As shown in Fig. 2C, the disintegration time of the tablets subjected to $1 \mathrm{~min}$ of microwave irradiation was greater than $120 \mathrm{~s}$. However, the disintegration times of the tablets subjected to microwave irradiation times of $2 \mathrm{~min}$ or more were less than $30 \mathrm{~s}$, and therefore well within the limits set by the FDA for ODTs. This decrease in the disintegration time can be explained in terms of the increase in the degree of swelling of the tablets subjected to 2 min of microwave irradiation, which would make it easier for water molecules to penetrate the tablets and result in the observed decrease in the disintegration time. As shown in Fig. 2D, the hardness of the tablets subjected to $1 \mathrm{~min}$ of microwave irradiation was $23 \mathrm{~N}$. However, the hardness values of the tablets subjected to 2 and $3 \mathrm{~min}$ of microwave irradiation were 13 and $14 \mathrm{~N}$, respectively. This result can be attributed to the decrease in the physical strength of the tablets as the number of voids in the tablets increases with their increased swelling. However, the hardness of the tablets subjected to $3.5 \mathrm{~min}$ of microwave irradiation was $28 \mathrm{~N}$, despite the degree of swelling of these tablets being $1.4 \mathrm{~mm}$. As shown in Fig. 2A, this result could be attributed to the tablet temperature reaching up to $160^{\circ} \mathrm{C}$, which would have resulted in the melting of mannitol (melting point $158^{\circ} \mathrm{C}$ ), and the formation of new bonds between the mannitol particles. It is noteworthy that several methods have been reported based on the melting points of the sugar alcohols used as excipients, which can lead to improvements in the tablet hardness properties following heat treatment. ${ }^{32)}$ As shown in Fig. 2E, the friability of the tablets that were not subjected to microwave irradiation was $0.6 \%$. The friability of the tablets subjected to the microwave irradiation process decreased depending on the microwave irradiation time, with the friability of the tablets reaching $0.1 \%$ after a microwave irradiation time of $3.5 \mathrm{~min}$.
Figure $2 \mathrm{~F}$ shows the $\mathrm{CFA}, \mathrm{CFB}$, Pre CFA and Pre CFB contents of the ODTTs prepared using a $1.68 \mathrm{M}$ solution of $\mathrm{Na}_{2} \mathrm{HPO}_{4} \cdot 12 \mathrm{H}_{2} \mathrm{O}$. The untreated ODTTs contained $0.36 \mu \mathrm{g}$ of CFA, $0.14 \mu \mathrm{g}$ of $\mathrm{CFB}, 3.6 \mu \mathrm{g}$ of Pre CFA and $2.8 \mu \mathrm{g}$ of Pre $\mathrm{CFB}$ in each tablet. Interestingly, the Pre CFA and Pre CFB contents of the tablets tended to decrease after a microwave irradiation period of $2 \mathrm{~min}$ or more, with only 0.05 and $0.26 \mu \mathrm{g}$ of Pre CFA and Pre CFB being detected after $3.5 \mathrm{~min}$ of microwave irradiation. Furthermore, the CFA and CFB contents of the tablets significantly increased after $3 \mathrm{~min}$ of microwave irradiation, with 2.5 and $1.5 \mu \mathrm{g}$ of CFA and CFB being detected, respectively. These results therefore demonstrated that the use of a $1.68 \mathrm{M}$ solution of $\mathrm{Na}_{2} \mathrm{HPO}_{4} \cdot 12 \mathrm{H}_{2} \mathrm{O}$ led to an increase in the conversion of Pre CFA and Pre CFB to CFA and CFB. However, there was a significant decrease in the CFA and CFB contents of the tablets after 3.5 min of microwave irradiation compared with $3 \mathrm{~min}$. This result was attributed to the decomposition of CFA and CFB because the tablet temperature exceeded $160^{\circ} \mathrm{C}^{30,31,33)}$ This result suggested that it would be particularly important to exert a strict level of control over the tablet temperature for the reaction, and that the tablets must not exceed $140^{\circ} \mathrm{C}$ to avoid the decomposition of the active ingredients.

In summary, these results show that the microwave irradiation of tablets prepared using a $1.68 \mathrm{M}$ solution of $\mathrm{Na}_{2} \mathrm{HPO}_{4} \cdot 12 \mathrm{H}_{2} \mathrm{O}$ for $3 \mathrm{~min}$ allowed for the formation ODTTs with a hardness of $14 \mathrm{~N}$, friability of $0.1 \%$ and disintegration time of $18 \mathrm{~s}$. These conditions also allowed for a significant enrichment in the CFA and CFB contents of the tablets.

Experimental Design As shown above, we have developed a new procedure for the preparation of ODTTs with excellent tablet properties and enhanced CFA and CFB contents by the microwave irradiation of wet molded tablets containing $\mathrm{Na}_{2} \mathrm{HPO}_{4} \cdot 12 \mathrm{H}_{2} \mathrm{O}$. In this section, we describe the optimization of the manufacturing conditions, including the granulation solvent, tableting pressure and powdered tea leaf content, using a face-centered cubic design to reveal the effects of these variables on the tablet properties and chafuroside content. The details of the tablet properties (i.e., swelling degree, tablet hardness, disintegration time, friability) and CFA, CFB, Pre CFA and Pre CFB contents of all 19 of the tablet batches prepared in this study are shown in Table 2. Multiple linear regression analysis was performed on all of these data. The significance of each operational factor and its effect on the tablet properties and chafuroside contents were determined and the results are shown in Table 3. Table 3 summarizes the coefficients, as well as the $p$-values obtained by Student's $t$-test to assess the significance of each term and the $R^{2}$ value, which can be used as an indicator of the fit of each linear regression equation. Furthermore, the response surface plots obtained from the multiple regression equations for the physical properties of the tablets are shown in Figs. 3A-D, and the details of the active ingredient contents are shown in Figs. 4A-D.

Table 3 shows that the granulation solvent volume $\left(X_{1}\right)$ had a significant positive effect on the degree of swelling of the tablets, whereas the tableting pressure $\left(X_{2}\right)$ and the content of the powdered tea leaves $\left(X_{3}\right)$ had significant negative effects on the degree of swelling. The results shown in Fig. 3A revealed the same tendencies. This result could be attributed to an increase in the size of the force being generated by the water vapor during the microwave irradiation process as the 
Table 2. Results for the Characterization of the ODTTs

\begin{tabular}{|c|c|c|c|c|c|c|c|c|c|c|c|}
\hline \multirow{2}{*}{$\begin{array}{l}\text { Batch } \\
\text { No. }\end{array}$} & \multicolumn{3}{|c|}{ Parameter } & \multirow{2}{*}{$\begin{array}{l}\text { Swelling degree } \\
(\mathrm{mm})\end{array}$} & \multirow{2}{*}{$\begin{array}{c}\text { Disintegration time } \\
\text { (s) }\end{array}$} & \multirow{2}{*}{$\begin{array}{l}\text { Hardness } \\
\text { (N) }\end{array}$} & \multirow{2}{*}{$\begin{array}{l}\text { Friability } \\
\quad(\%)\end{array}$} & \multirow{2}{*}{$\begin{array}{c}\text { Pre CFA } \\
(\mu \mathrm{g})\end{array}$} & \multirow{2}{*}{$\begin{array}{l}\text { Pre CFB } \\
\quad(\mu \mathrm{g})\end{array}$} & \multirow{2}{*}{$\begin{array}{l}\text { CFA } \\
(\mu \mathrm{g})\end{array}$} & \multirow{2}{*}{$\begin{array}{l}\text { CFB } \\
(\mu \mathrm{g})\end{array}$} \\
\hline & $X_{1}$ & $X_{2}$ & $X_{3}$ & & & & & & & & \\
\hline 1 & -1 & -1 & -1 & 1.60 & 10 & 7 & 0.77 & 0.83 & 1.35 & 2.18 & 1.20 \\
\hline 2 & +1 & -1 & -1 & 1.78 & 7 & 6 & 1.12 & 0.73 & 1.15 & 2.18 & 1.19 \\
\hline 3 & -1 & +1 & -1 & 1.38 & 12 & 16 & 0.59 & 0.64 & 1.20 & 1.95 & 1.42 \\
\hline 4 & +1 & +1 & -1 & 1.52 & 12 & 12 & 0.80 & 0.75 & 1.23 & 2.23 & 1.21 \\
\hline 5 & -1 & -1 & +1 & 0.88 & 33 & 12 & 0.52 & 2.42 & 3.55 & 4.47 & 2.24 \\
\hline 6 & +1 & -1 & +1 & 0.99 & 28 & 9 & 1.56 & 2.98 & 3.94 & 4.21 & 1.81 \\
\hline 7 & -1 & +1 & +1 & 0.66 & 34 & 16 & 0.55 & 3.92 & 4.03 & 3.21 & 1.30 \\
\hline 8 & +1 & +1 & +1 & 0.75 & 28 & 14 & 0.88 & 1.24 & 2.46 & 4.97 & 2.95 \\
\hline 9 & -1 & 0 & 0 & 1.20 & 25 & 12 & 0.16 & 2.24 & 2.90 & 3.05 & 1.29 \\
\hline 10 & +1 & 0 & 0 & 1.50 & 12 & 11 & 0.60 & 1.36 & 2.43 & 3.65 & 1.98 \\
\hline 11 & -1 & 0 & 0 & 1.48 & 20 & 12 & 0.61 & 1.70 & 2.34 & 3.21 & 1.48 \\
\hline 12 & 0 & -1 & 0 & 1.32 & 22 & 15 & 0.40 & 0.55 & 2.15 & 3.13 & 1.92 \\
\hline 13 & 0 & 0 & -1 & 1.42 & 12 & 11 & 0.37 & 0.56 & 1.31 & 2.63 & 1.56 \\
\hline 14 & 0 & 0 & +1 & 0.82 & 34 & 15 & 1.10 & 4.13 & 4.73 & 4.20 & 1.77 \\
\hline 15 & 0 & 0 & 0 & 1.29 & 18 & 14 & 0.00 & 1.62 & 2.31 & 3.06 & 1.61 \\
\hline 16 & 0 & 0 & 0 & 1.39 & 18 & 15 & 0.20 & 1.54 & 2.19 & 2.99 & 1.37 \\
\hline 17 & 0 & 0 & 0 & 1.35 & 14 & 13 & 0.43 & 1.39 & 1.97 & 2.80 & 1.26 \\
\hline
\end{tabular}

Table 3. Results of Multiple Regression Analysis for the Tablet Properties

\begin{tabular}{|c|c|c|c|c|c|c|c|c|}
\hline \multirow{2}{*}{ Term } & \multicolumn{2}{|c|}{ Swelling degree } & \multicolumn{2}{|c|}{ Disintegration time } & \multicolumn{2}{|c|}{ Hardness } & \multicolumn{2}{|c|}{ Friability } \\
\hline & Coefficient & $p$-Value & Coefficient & $p$-Value & Coefficient & $p$-Value & Coefficient & $p$-Value \\
\hline$X_{1}$ & 0.082 & 0.005 & -2.669 & 0.029 & -1.100 & 0.023 & 0.237 & 0.013 \\
\hline$X_{2}$ & -0.110 & 0.001 & - & - & 2.700 & $<0.001$ & - & - \\
\hline$X_{3}$ & -0.360 & $<0.001$ & 8.187 & $<0.001$ & 1.400 & - & - & - \\
\hline$X_{1} X_{2}$ & - & - & - & - & - & 0.008 & - & - \\
\hline$X_{1} X_{3}$ & - & - & - & - & - & - & - & - \\
\hline$X_{2} X_{3}$ & - & - & - & - & 0.257 & 0.122 & - & - \\
\hline$X_{1}^{2}$ & - & - & - & - & -0.168 & 0.036 & - & - \\
\hline$X_{2}^{2}$ & - & 0.157 & - & - & - & - & - & - \\
\hline$X_{3}^{2}$ & -0.229 & 0.001 & -1.520 & 0.163 & - & - & 0.387 & 0.027 \\
\hline Constant & 1.341 & - & 18.568 & - & 13.662 & & 0.289 & - \\
\hline$R^{2}$ & & 0.962 & & 0.883 & & 0.832 & & 0.661 \\
\hline \multirow{2}{*}{ Term } & \multicolumn{2}{|c|}{ Pre CFA } & \multicolumn{2}{|c|}{ Pre CFB } & \multicolumn{2}{|c|}{ CFA } & \multicolumn{2}{|c|}{$\mathrm{CFB}$} \\
\hline & Coefficient & $p$-Value & Coefficient & $p$-Value & Coefficient & $p$-Value & Coefficient & $p$-Value \\
\hline$X_{1}$ & - & - & - & - & 0.238 & 0.059 & - & - \\
\hline$X_{2}$ & - & - & - & - & - & - & - & - \\
\hline$X_{3}$ & 1.118 & 0.001 & 1.247 & $<0.05$ & 0.989 & $<0.05$ & 0.349 & 0.026 \\
\hline$X_{1} X_{2}$ & -0.379 & 0.158 & - & - & 0.288 & 0.045 & 0.235 & 0.133 \\
\hline$X_{1} X_{3}$ & - & - & - & - & - & - & - & - \\
\hline$X_{2} X_{3}$ & - & - & - & - & - & - & - & - \\
\hline$X_{1}^{2}$ & - & - & - & - & - & - & - & - \\
\hline$X_{2}^{2}$ & -0.608 & 0.186 & - & - & - & - & - & - \\
\hline$X_{3}^{2}$ & 0.612 & 0.183 & - & - & - & - & - & - \\
\hline Constant & 1.640 & - & - & - & 3.144 & - & 1.528 & - \\
\hline$R^{2}$ & & 0.634 & & 0.791 & & 0.866 & & 0.314 \\
\hline
\end{tabular}

amount of granulation solvent increased. This would also result in attenuated resistance to the water vapor as the tableting pressure decreased. The degree of swelling decreased as the content of the powdered tea leaves increased, which suggested that the swelling of the tablets was being suppressed by the fluidity of the powdered tea leaves. The content of the powdered tea leaves $\left(X_{3}\right)$ had a significant positive effect on the disintegration time, whereas the volume of the granulation solvent $\left(X_{1}\right)$ had a significant negative effect on the disintegration time (Table 3). The results shown in Fig. 3B revealed a similar tendency. These results therefore indicated that the disintegration time was more sensitive to the amount of 
A
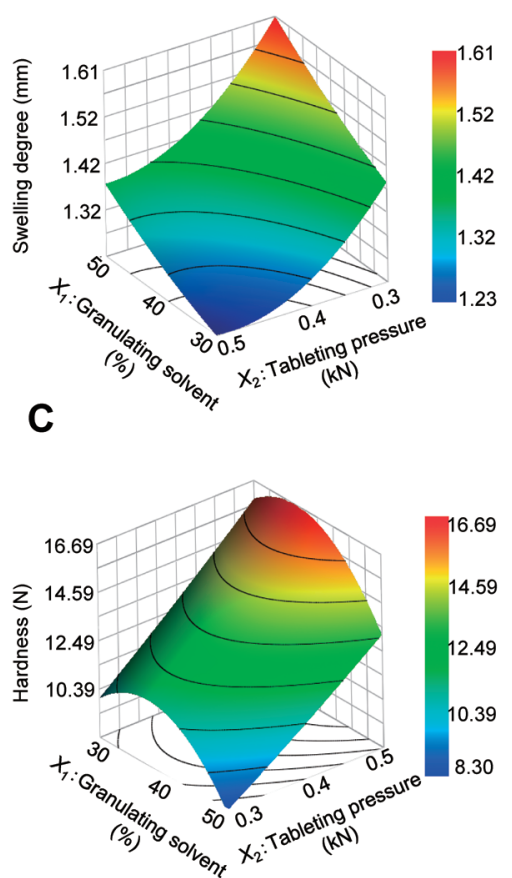

B
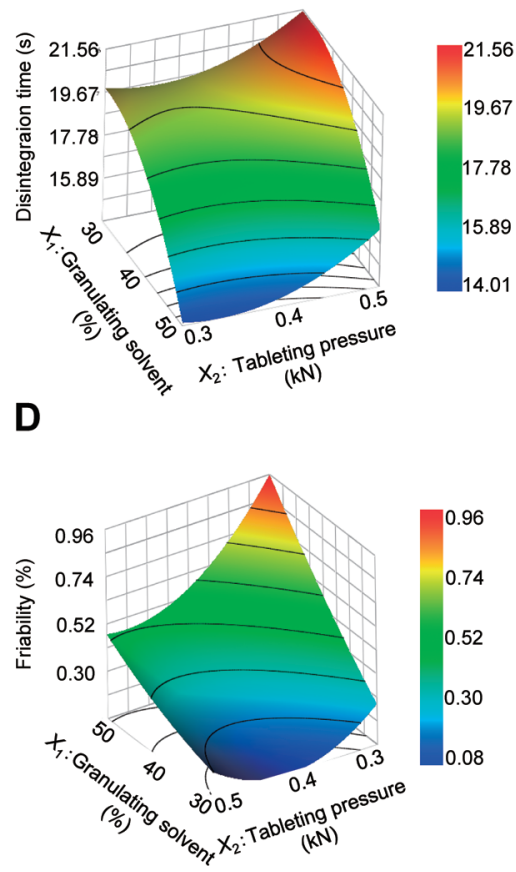

Fig. 3. Response Surface Plots for the Physicochemical Properties of the ODTTs Manufactured Using a $1.68 \mathrm{M} \mathrm{Na} \mathrm{NPO}_{4} \cdot 12 \mathrm{H}_{2} \mathrm{O}$ Solution and a Fixed Powdered Tea Leaf Content $\left(X_{3}\right)$ of $32 \%$

(A) Swelling degree, (B) disintegration time, (C) hardness and (D) friability of response surface plots.

A
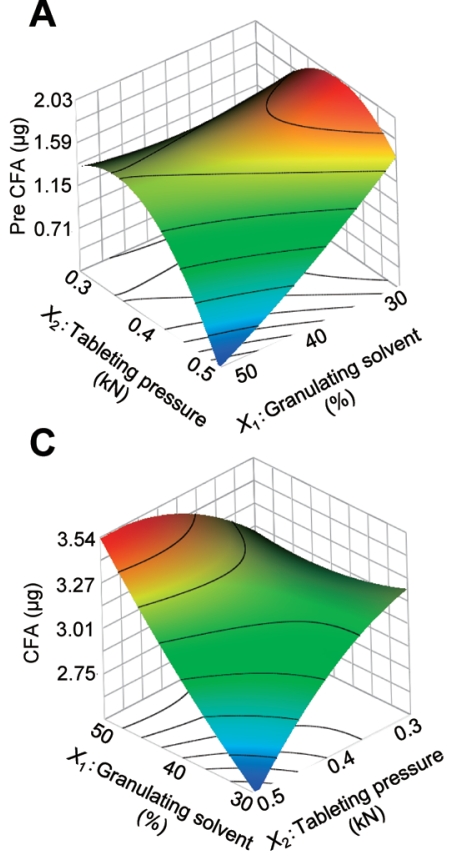

B
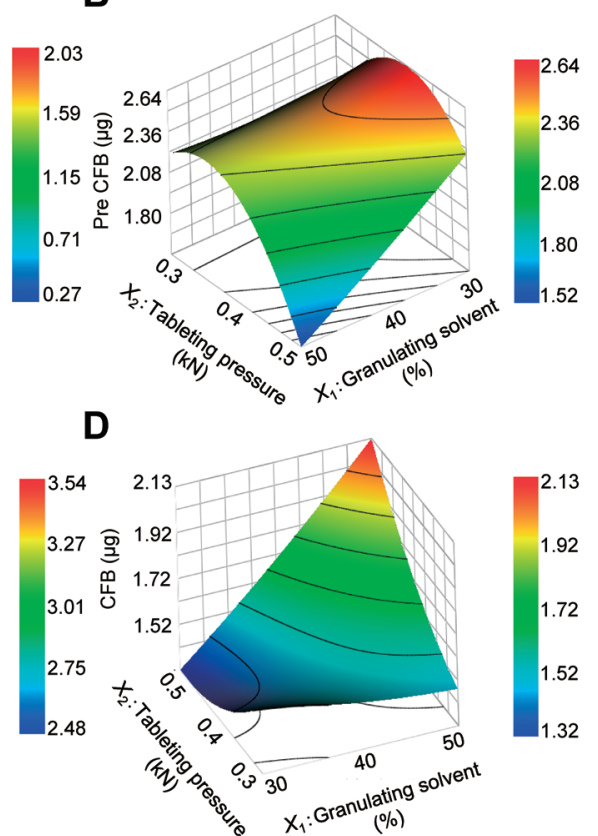

Fig. 4. Response Surface Plots of the Chafuroside Contents Contained in the ODTTs Manufactured Using a $1.68 \mathrm{M} \mathrm{Na}_{2} \mathrm{HPO}_{4} \cdot 12 \mathrm{H}_{2} \mathrm{O}$ Solution and a Fixed Powdered Tea Leaf Content $\left(X_{3}\right)$ of $32 \%$

(A) Pre CFA, (B) Pre CFB, (C) CFA and (D) CFB response surface plots.

granulation solvent than the tableting pressure, and that the disintegration time would increase significantly as the powdered tea leaf content increased. The tableting pressure $\left(X_{2}\right)$ and the content of the powdered tea leaves $\left(X_{3}\right)$ had significant positive effects on the tablet hardness, whereas the amount of granulation solvent $\left(X_{1}\right)$ had a significant negative effect on the same variable (Table 3). This result was attributed to there being a decrease in the degree of swelling as the content of the powdered tea leaves increased, with insufficient swelling leading to low tablet hardness. As shown in Fig. 3C, the tablet hardness appeared to reach its maximum value when the volume of granulation solvent reached $40 \%$, which suggested that 
the addition of a smaller volume of granulation solvent would not lead to the formation of solid bridges. Furthermore, these results suggested that the addition of an excess of the granulation solvent would lead to low tablet hardness because of more swelling. The amount of granulation solvent $\left(X_{1}\right)$ had a significant positive effect on the friability (Table 3). As shown in Fig. 3D, this tendency was contrary to the result obtained using the response surface method of tablet hardness. These results therefore suggested that although an interaction was not observed for each variable, each of these variables had an effect on the properties of the different tablets.

As expected, the content of the powdered tea leaves $\left(X_{3}\right)$ had a significant effect on the amounts of all of the components in the tablets. For the CFA content, a positive interaction was observed between the amount of granulation solvent $\left(X_{1}\right)$ and the tableting pressure $\left(X_{2}\right)$ (Table 3). As shown in Figs. 4A-D, the reactions for the conversion of Pre CFA and Pre CFB to CFA and CFB were dependent on the tableting pressure and the amount of granulation solvent. Interestingly, when the volume of granulation solvent and tableting pressure were too high, the Pre CFA and Pre CFB contents tended to decrease, while the CFA and CFB contents tended to increase. This result could be attributed to the even distribution of the salt solution in the tablets because of the tableting pressure being too high, which would suggest that the reactions required for these conversion processes were occurring throughout the entire tablet.

Process Optimization Based on the results of the multiple regression analysis, a design space that satisfied the following criteria was obtained by fixing the powdered tea leaf content at $32 \%$ (Fig. 5).

1) The tablet hardness must be greater than $13 \mathrm{~N}$.

2) The disintegration time must be less than $30 \mathrm{~s}$.

3) The friability must be less than $0.5 \%$.

Especially, as for the criteria of tablet hardness (greater than $13 \mathrm{~N}$ ), this value against tablet with a diameter of $5 \mathrm{~mm}$ used in this study could be regarded as greater than $30 \mathrm{~N}$ when assuming the general tablet with a diameter of $9 \mathrm{~mm}$, using a formula of the tensile strength $(\sigma)(\mathrm{MPa})(\sigma=2 F / \pi D t)(F(\mathrm{~N})$, tablet fracture strength; $D(\mathrm{~mm})$, the diameter of the tablets; and $t(\mathrm{~mm})$, the thickness of the tablets). ${ }^{34)}$ The central portion of the design space afforded the optimized operational conditions, which were determined to be as follows: $X_{1}$ (the amount of granulation solvent) $=45 \% ; X_{2}$ (tableting pressure) $=0.43 \mathrm{kN}$; and $X_{3}$ (content of the powdered tea leaves) $=32 \%$. To validate the model, we measured the tablet properties and active ingredient contents of the ODTTs prepared under the optimized operational conditions. As shown in Table 4, there was a good correlation between the predicted values and the experimental values for the responses to the tablet properties. These results therefore demonstrated that the operational conditions had been optimized accurately using the experimental design method. However, some errors were observed with respect to the CFA, CFB, Pre CFA and Pre CFB contents. The reason for these errors could be attributed to the conversion from Pre CFA and Pre CFB to CFA and CFB being largely dependent on the temperature. With this in mind, it is important to mention that the microwave irradiation time used in this study was different for each batch because the microwave irradiation time was set to the time at which the tablet temperature reached $135-145^{\circ} \mathrm{C}$. However, it is very likely that ODTTs

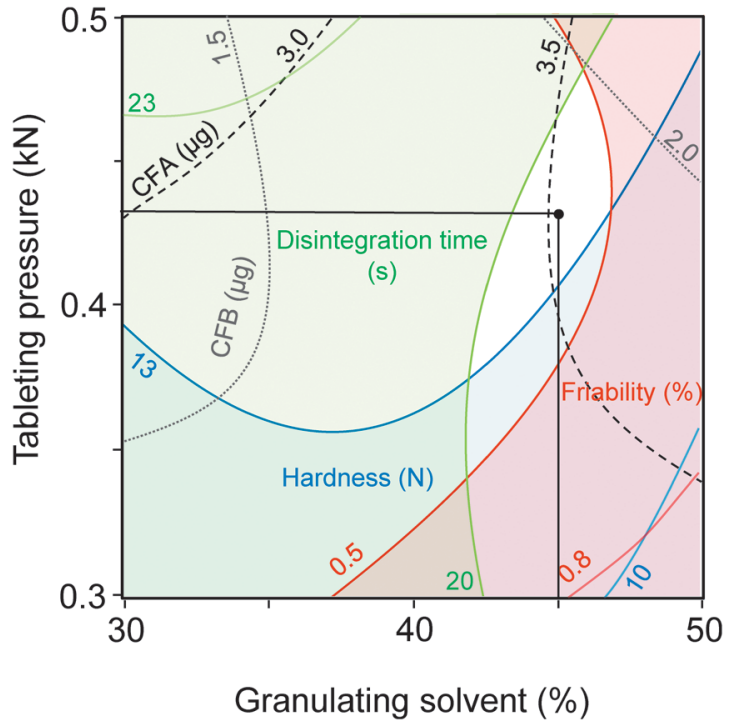

Fig. 5. Contour Plots of Tablet Disintegration Time, Hardness and Friability

The white space indicate the design space that satisfied the following criteria: tablet hardness greater than $13 \mathrm{~N}$, disintegration time less than $30 \mathrm{~s}$ and friability less than $0.5 \%$ by fixing the powdered tea leaf content $\left(X_{3}\right)$ to $32 \%$. The intersecting point of the straight line shows the optimized operating point.

Table 4. Optimization and Validation of the Statistical Model

\begin{tabular}{lccc}
\hline \hline Item & $\begin{array}{c}\text { Predicted } \\
\text { value }\end{array}$ & $\begin{array}{c}\text { Experimental } \\
\text { value }\end{array}$ & Residual \\
\hline Swelling degree $(\mathrm{mm})$ & 1.27 & 1.24 & -0.03 \\
Disintegration time $(\mathrm{s})$ & 19.4 & 20.0 & 0.6 \\
Hardness $(\mathrm{N})$ & 13.6 & 12.6 & -1.0 \\
Friability $(\%)$ & 0.45 & 0.45 & 0 \\
Pre CFA $(\mu \mathrm{g})$ & 1.6 & 1.6 & 0 \\
Pre CFB $(\mu \mathrm{g})$ & 2.5 & 2.9 & 0.4 \\
CFA $(\mu \mathrm{g})$ & 3.5 & 3.0 & -0.5 \\
$\mathrm{CFB}(\mu \mathrm{g})$ & 1.8 & 1.4 & -0.4 \\
\hline
\end{tabular}

containing specific amounts of CFA and CFB could be prepared in high quality using a microwave device that is capable of temperature control. In fact, microwave devices that are capable of temperature control have been used in the food industry. The expansion of this method to the production-scale manufacture of ODTTs could therefore be possible.

Recently, a microwave-assisted method has been applied for the efficient extraction of tea polyphenols from green tea leaves, ${ }^{35)}$ indicating a possibility that in our microwave-assisted manufacturing process of ODTTs, CFA and CFB could be efficiently extracted from powdered tea leaves and dissolved in the medium and/or oral cavity because the powdered tea leaves itself becomes fragile under high temperature conditions by microwave irradiation. Further studies such as in vitro dissolution experiments as well as in vivo pharmacological experiments using inflammation-induced animal models would therefore prove the usefulness of ODTTs and offer improved levels of QOL to patients.

\section{Conclusion}

A microwave treatment process was applied to wet molded tablets in the current study to allow for the preparation of ODTTs with enriched levels of CFA and CFB and excellent 
tablet properties. Distilled water was initially used as a granulation solvent for the preparation of the ODTTs by microwave irradiation. This method led to a significant increase in the tablet hardness depending on the microwave irradiation time, with the hardness of the tablets reaching $44 \mathrm{~N}$ after 4 min of microwave irradiation. However, the disintegration times of the tablets subjected to $2 \mathrm{~min}$ or more of the microwave irradiation process were much greater than $120 \mathrm{~s}$. In addition, the CFA and CFB contents of these tablets, which are both strong anti-inflammatory agents, did not increase during the microwave irradiation process, which suggested that the reactions responsible for the conversion of Pre CFA and Pre CFB to $\mathrm{CFA}$ and $\mathrm{CFB}$ were not enhanced under these conditions. The failure of this process to increase the CFA and CFB contents of the tablets was attributed to the tablet temperature not being high enough to affect these transformations. To increase the tablet temperature, we used a $1.68 \mathrm{M}$ solution of $\mathrm{Na}_{2} \mathrm{HPO}_{4} \cdot 12 \mathrm{H}_{2} \mathrm{O}$ as the adsorption and granulation solvents instead of distilled water. This change in the solvents led to a significant increase in the tablet temperature up to $140^{\circ} \mathrm{C}$ following $3 \mathrm{~min}$ of microwave irradiation. As the tablet temperature increased so too did the degree of swelling, which reached over $1 \mathrm{~mm}$ and resulted in a disintegration time of less than $30 \mathrm{~s}$. At the same time, the CFA and CFB contents of the tablets reached their maximum values of 3 and $1.5 \mu \mathrm{g}$ after 3 min of microwave irradiation. Compared with the untreated tablets, the CFA and CFB contents of the microwave-treated samples increased by about 7- and 11-fold, respectively, which suggested that the reactions responsible for the conversion of Pre CFA and Pre CFB to CFA and CFB were enhanced by the process. Thus, controlling the tablet temperature during the microwave irradiation by adding a salt solution not only led to a significant improvement in the properties of the ODTTs but also allowed for the conversion of Pre CFA and Pre CFB to CFA and CFB. The operational conditions were also optimized by face-centered composite design. This process led to the developed of an optimized process capable of satisfying the following criteria: tablet hardness greater than $13 \mathrm{~N}$, disintegration time less than $30 \mathrm{~s}$ and friability less than $0.5 \%$. These values corresponded to $X_{1}$ (the amount of granulation solvent), $X_{2}$ (tableting pressure) and $X_{3}$ (content of the powdered tea leaves) values of $45 \%, 0.43 \mathrm{kN}$ and $32 \%$, respectively. These results therefore show that the ODTTs prepared in the current study have excellent tablet properties and contain enriched levels of CFA and CFB when they were prepared under the optimized operational conditions. To the best of our knowledge, this study showed for the first time, that ODTs containing powdered tea leaves with enriched levels of active ingredients and excellent tablet properties can be successfully prepared by using the microwave irradiation technique. We strongly suggest that this procedure would have high potential to prepare ODTs containing powdered tea leaves as well as other plant-derived powders such as natural medicines.

Conflict of Interest The authors declare no conflict of interest.

\section{References}

1) Moore R. J., Jackson K. G., Minihane A. M., Br. J. Nutr., 102, 1790-1802 (2009).

2) Ojo O. O., Ladeji O., Nadro M. S., J. Med. Food, 10, 345-349 (2007).

3) Sadzuka Y., Sugiyama T., Miyagishima A., Nozawa Y., Hirota S., Cancer Lett., 105, 203-209 (1996).

4) Sadzuka Y., Sugiyama T., Sonobe T., Cancer Lett., 158, 119-124 (2000).

5) Li M., Zhang J. H., Zhu K. X., Peng W., Zhang S. K., Wang B., Zhu Y. J., Zhou H. M., LWT-Food Sci. Technol., 46, 23-28 (2011).

6) Koo M. W., Cho C. H., Eur. J. Pharmacol., 500, 177-185 (2004).

7) Hara Y., Pharmacol. Res., 64, 100-104 (2011).

8) Sastry S. V., Nyshadham J. R., Fix J. A., Pharm. Sci. Technol. Today, 3, 138-145 (2000)

9) Shoriken K., Yamaguchi M., Nakata H., Jpn. J. Pharm. Health Care Sci., 29, 648-651 (2003)

10) Carnaby-Mann G., Crary M., Arch. Otolaryngol. Head Neck Surg., 131, 970-975 (2005).

11) Perrie Y., Badhan R. K., Kirby D. J., Lowry D., Mohammed A. R., Ouyang D., J. Control. Release, 161, 389-398 (2012).

12) Seager H., J. Pharm. Pharmacol., 50, 375-382 (1998).

13) Lafon L., US Patent 4616047 (1986).

14) Tsushima Y., J. Pharm. Mache. Eng., 21, 337-347 (2012).

15) Humbert-Droz P., Seidel M., Martani R., US Patent 6083531 (2000).

16) Segado F. J., WO2003103629 A1 (2005).

17) Teunou E., Fitzpatrick J. J., Synnott E. C., J. Food Eng., 39, 31-37 (1999).

18) Sano S., Iwao Y., Kimura S., Itai S., Int. J. Pharm., 416, 252-259 (2011).

19) Sano S., Iwao Y., Noguchi S., Kimura S., Itai S., Int. J. Pharm., 448, 132-141 (2013).

20) Sano S., Iwao Y., Kimura S., Noguchi S., Itai S., Int. J. Pharm., 468, 234-242 (2014).

21) Ortiz J., Kestur U. S., Taylor L. S., Mauer L. J., J. Agric. Food Chem., 57, 4691-4697 (2009).

22) Ishida H., WO 2010076879 A1 (2013).

23) Ishida H., Wakimoto T., Kitao Y., Tanaka S., Miyase T., Nukaya H., J. Agric. Food Chem., 57, 6779-6786 (2009).

24) Furuta T., Kimura T., Kondo S., Mihara H., Wakimoto T., Nukaya H., Tsuji K., Tanaka K., Tetrahedron, 60, 9375-9379 (2004).

25) Muta K., Yokoo M., Ishida H., JP 2013095733 A (2013).

26) Hasegawa T., Shimada S., Ishida H., Nakashima M., PLoS ONE, 8, e77308 (2013)

27) Hoashi Y., Tozuka Y., Takeuchi H., Chem. Pharm. Bull., 61, $962-$ 966 (2013).

28) Park D. J., Imm J. Y., Ku K. H., J. Food Sci., 66, $793-798$ (2001).

29) DiGuilio R. M., Teja A. S., Ind. Eng. Chem. Res., 31, 1081-1085 (1992).

30) Ishida H., JP 2012125217 A (2012a).

31) Ishida H., JP 2012126690 A (2012b).

32) Kuno Y., Kojima M., Ando S., Nakagami H., J. Control. Release, 105, 16-22 (2005)

33) Nukaya H., Ishida H., JP 2009131161 A (2012).

34) Fell J. T., Newton J. M., J. Pharm. Sci., 59, 688-691 (1970).

35) Nkhili E., Tomao V., El Hajji H., El Boustani E. S., Chemat F., Dangles O., Phytochem. Anal., 20, 408-415 (2009). 